Check for updates

Cite this: RSC Adv., 2017, 7, 25362

Received 6th September 2016

Accepted 6th April 2017

DOI: $10.1039 / \mathrm{c} 6 \mathrm{ra} 22311 \mathrm{~g}$

rsc.li/rsc-advances

\section{The re-strengthening effect of a quenching process on the mechanical and tribological performance of electrodeposited $\mathrm{Ni}-\mathrm{P}$ coatings on steel substrates}

\author{
Ruishan Li, ${ }^{\text {ab Hua Yang, }}{ }^{\text {ab }}$ Youcai Feng, ${ }^{\text {ab }}$ Dongshan Li, (D) *c Guang'an Zhang*c \\ and Peizeng Zhang ${ }^{\text {d }}$
}

$\mathrm{Ni}-\mathrm{P}$ alloy coatings with a phosphorus content of $4.44 \mathrm{wt} \%$ were prepared by the direct current electrodeposition technique. After being annealed at $400{ }^{\circ} \mathrm{C}$, all the $\mathrm{Ni}-\mathrm{P}$ coatings mainly exhibited a nanocrystalline structure comprising nanocrystalline $\mathrm{Ni}$ and $\mathrm{Ni}_{3} \mathrm{P}$ precipitates. The $\mathrm{Ni}-\mathrm{P}$ coatings were further subjected to quenching treatment at various temperatures. The effects of the quenching process on the microstructural evolution and tribological properties of the $\mathrm{Ni}-\mathrm{P}$ coatings were investigated. A further quenching process at $400{ }^{\circ} \mathrm{C}$ caused a decrease in grain size as well as increases in hardness and wear resistance, which was attributed to the re-strengthening effect of the combination of the grain refinement effect and the dispersion of $\mathrm{Ni}_{3} \mathrm{P}$. The wear resistance of the quenched $\mathrm{Ni}-\mathrm{P}$ coatings increased with a decrease in grain size in accordance with the inverse Hall-Petch relationship.

\section{Introduction}

The electrodeposition of coatings on many engineering components effectively represents an ideal process for protecting substrates from corrosion and wear when subjected to many types of stringent operating condition. ${ }^{1,2}$ In various kinds of coating, nickel-phosphorus (Ni-P) films are widely adopted for many industrial applications including machinery in the automotive, aviation, printing and chemical industries owing to their merits such as high hardness, lubricity, corrosion and wear resistance and other superior mechanical properties..$^{3-5}$ Moreover, the hardness of Ni-P alloys can be further enhanced by the precipitate strengthening effect as a result of a postannealing process. Many efforts have been made to investigate the influence of annealing processes on the mechanical and tribological performance of Ni-P alloys. Among these, the stability of coatings during annealing processes was mainly studied. For example, Ahmad et al. reported that as-plated amorphous Ni-P coatings crystallized to form tetragonal $\mathrm{Ni}_{3} \mathrm{P}$ and metallic $\mathrm{Ni}$ after being annealed at $275-300{ }^{\circ} \mathrm{C} .{ }^{6}$ According to a report by Mehta et al., $\mathrm{Ni}_{3} \mathrm{P}$ precipitates were usually located at triple junctions and inside a few grains, which effectively

\footnotetext{
${ }^{a}$ State Key Laboratory of Advanced Processing and Recycling of Nonferrous Metals, Lanzhou University of Technology, Lanzhou 730050, China

${ }^{5}$ School of Science, Lanzhou University of Technology, Lanzhou 730050, China

'State Key Laboratory of Solid Lubrication, Lanzhou Institute of Chemical Physics, Chinese Academy of Sciences, Lanzhou 730000, China. E-mail: ononlds@126.com; Fax: +869314968117

${ }^{d}$ Basic Courses Department of Lanzhou Institute of Technology, Lanzhou 730050, China
}

inhibited the grain growth of Ni-P alloys and hence resulted in a strengthening effect. ${ }^{7}$

During practical operations, many engineering components often encounter sudden variations in temperature, which may subsequently cause changes in the structure and properties of coatings. Nevertheless, there have been a very small number of investigations into hardening heat treatment, including quenching and tempering. In practice, the production of coatings at temperatures of above $500{ }^{\circ} \mathrm{C}$, as well as the possibility of subjecting them to a thermal shock such as quenching, have not yet been fully investigated. Tanabe et al. studied a great improvement in the adhesive strength of ceramic-coated steels achieved without compromising the film hardness by employing a laser quenching process. ${ }^{8}$ According to the results of a study conducted by Razavi et al., the hardness and anti-corrosion behavior of a laser gas nitrided surface were greatly enhanced by the laser quenching process and nitridation of the surface. ${ }^{9}$ Qiu et al. reported the effects of thermal quenching on the surface morphology and structure of FePt/TiN films. The film surface morphology became smooth upon rapid quenching, and the grain structure was refined and the degree of order in the annealed films was greatly improved by rapid quenching. ${ }^{10}$ These results demonstrated that the quenching process could play a significant role in the strengthening effect on the hardness, toughness, and wear resistance while minimizing residual stress and the possibility of cracking of various coatings. Therefore, it is considered that an investigation of the relationship between the quenching process and the properties of $\mathrm{Ni}-\mathrm{P}$ coatings would create the possibility of improving the working performance of a large number of nickel-based coatings. However, the related phenomena and mechanisms still lack systematic research. 
In this work, we electrodeposited $\mathrm{Ni}-\mathrm{P}$ alloy coatings on interstitial-free (IF) steel substrates by the direct current electrodeposition technique. IF steel is widely employed in the manufacture of machinery for the automotive, aviation, printing and chemical industries owing to its high strength and good deepdrawing properties. $^{11}$ It was chosen as a representative substrate because in these applications, in particular the automotive and aviation industries, sudden changes in environmental temperature must be taken into account. The Ni-P alloy coatings were first subjected to an annealing process to improve their crystallinity and then quenched at various temperatures. The main objective of the present work was to study the effects of different quenching temperatures on the microstructural transformation and performance of Ni-P alloy coatings, to clarify the re-strengthening effect on their mechanical and tribological properties, and to further confirm the substantial interaction between the grain size and the precipitate re-strengthening effect in the electrodeposited Ni-P alloys.

\section{Experimental}

\subsection{Electrodeposition process}

$\mathrm{Ni}-\mathrm{P}$ coatings were obtained on IF steel substrates by the direct current electrodeposition technique. A nickel plate of a purity of $99.99 \%$ with dimensions of $60 \mathrm{~mm} \times 30 \mathrm{~mm} \times 2 \mathrm{~mm}$ was used as the anode. The substrate, which was used as the cathode, was a circular disc of a diameter of $26 \mathrm{~mm}$ and a thickness of $8 \mathrm{~mm}$. Before electrodeposition, the substrate was subjected to a series of conventional polishing and cleaning procedures, including mechanical polishing with 600 and 1200 grade SiC papers, ultrasonic degreasing in acetone, pre-cleaning in a solution containing sodium carbonate, sodium hydroxide and sodium lauryl sulphate to remove stains and oxide layers, rinsing with redistilled water, and rinsing with $5 \% \mathrm{H}_{2} \mathrm{SO}_{4}$. The steel substrate was then immersed immediately into the plating bath as the cathode. The composition of the electrolyte and the operating conditions are summarized in Table 1 . The electrolyte was placed inside a glass chamber and stirred until thoroughly mixed. The electrodeposition was conducted for $1 \mathrm{~h}$ in air.

\subsection{Heat treatments}

It has previously been reported that the hardness of $\mathrm{Ni}-\mathrm{P}$ coatings can be further enhanced by heat treatment as a result

Table 1 Chemical composition of the Ni-P electrolyte and direct current operating conditions

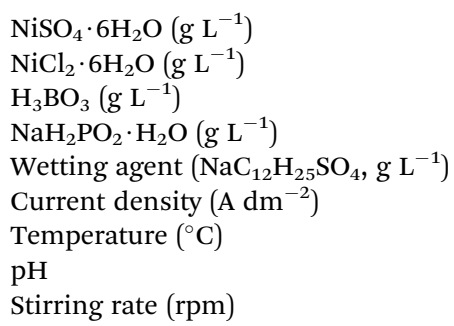

of the precipitation of a hard $\mathrm{Ni}_{3} \mathrm{P}$ phase. ${ }^{7}$ Hence, the asdeposited Ni-P alloy coatings were subjected to annealing at $400{ }^{\circ} \mathrm{C}$ for $1 \mathrm{~h}$ in a hot air oven at a heating rate of $5{ }^{\circ} \mathrm{C} \mathrm{min}^{-1}$ and then cooled in air to room temperature. To investigate the effects of sudden changes in temperature on the microstructure and performance of the coatings, the annealed samples were then heat-treated at a heating rate of $5{ }^{\circ} \mathrm{C} \mathrm{min}^{-1}$ from room temperature to the desired temperature plateau in the range from $300{ }^{\circ} \mathrm{C}$ to $700{ }^{\circ} \mathrm{C}$, which was maintained for a duration of $1 \mathrm{~h}$, and then immersed in cooling water for a period of less than $10 \mathrm{~s}$.

\subsection{Characterization}

The surface morphologies of the samples were observed with a JSM-5600 LV scanning electron microscope (SEM). The chemical compositions of the Ni-P coatings were characterized using a Kevex Sigma energy-dispersive X-ray spectrometer (EDS). The phase transformations of the Ni-P coatings were studied by $\mathrm{X}$-ray diffraction (XRD) with $\mathrm{Cu} \mathrm{K} \alpha$ radiation before and after the quenching process at different temperatures.

Microhardness was measured with a LECO LM247 Vickers indenter with an applied load of $50 \mathrm{~g}$, which was applied 10 times. All the microhardness values of the samples were recorded as the average of 10 measurements for each sample. The adhesive strength was measured by scratch testing in diamond indentation experiments with testing conditions of a distance of $5 \mathrm{~mm}$ and a load of $1 \mathrm{~N}$ to $100 \mathrm{~N}$.

The dry sliding behavior of the samples was tested using a CSM Instruments Tribo-S-D-0000 linear reciprocating tribometer at room temperature. The testing conditions comprised a single distance of $5 \mathrm{~mm}$, a reciprocating frequency of $5 \mathrm{~Hz}$, an applied load of $2 \mathrm{~N}$, a velocity of $7.8 \mathrm{~cm} \mathrm{~min}^{-1}$, and a sliding distance of $300 \mathrm{~m}$. The CSM Instruments reciprocating tribometer recorded the friction coefficient and sliding distance automatically during the test. All the experiments were conducted in an open atmosphere. The variation in humidity from $35 \%$ to $45 \%$ was dependent on the climatic conditions. The formula $K=V / S F$ was used to calculate the wear rate, where $V$ is the wear volume $\left(\mathrm{mm}^{3}\right), S$ is the total sliding distance $(\mathrm{m})$, and $F$ is the normal load $(\mathrm{N})$. Both the wear track morphology and the wear mechanism were observed by SEM.

\section{Results and discussion}

\subsection{Characterization of the as-deposited $\mathrm{Ni}-\mathrm{P}$ coatings}

SEM was used to determine the surface morphology and thickness, as well as the adhesion state between the coating and substrate. As seen in Fig. 1(a), the coating surface consists of numerous grains of nanometer size, which thereby make the coating dense and smooth in appearance, except for some micron-sized wrinkles and dispersed particles. Fig. 1(b) shows a cross-sectional SEM image of the as-deposited Ni-P coating with an average thickness of $16 \pm 1 \mu \mathrm{m}$. There are no obvious pores or cracks, which suggests a tightly coalescent joint at the coating-substrate interface. The clean and smooth topography of the sample indicates that the Ni-P coating and the IF steel 

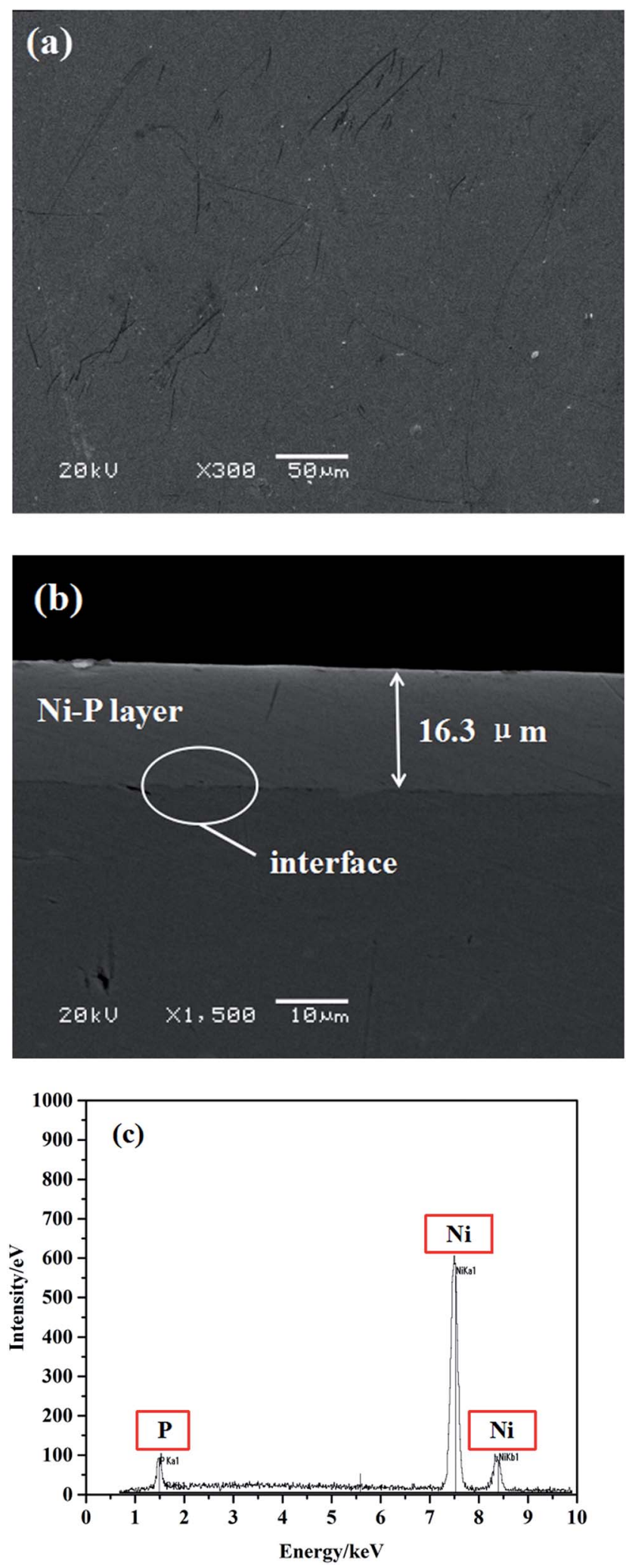

Fig. 1 (a) SEM micrograph of the as-deposited $\mathrm{Ni}-\mathrm{P}$ coating. (b) Typical cross-sectional SEM image of Ni-P coated IF steel. (c) Corresponding EDS spectrum showing the chemical composition of the as-deposited $\mathrm{Ni}-\mathrm{P}$ coating. base are physically bonded together. As seen in Fig. 1(c), the corresponding EDS analysis shows that the as-deposited Ni-P coatings mainly consist of $95.56 \mathrm{wt} \% \mathrm{Ni}$ and $4.44 \mathrm{wt} \% \mathrm{P}$. Other groups have reported that the incorporation of $\mathrm{P}$ would cause lattice disorder in the crystalline nickel matrix owing to the lower solubility of elemental phosphorus, and thus the higher the $\mathrm{P}$ content was in the as-deposited Ni-P coatings, the greater would be the lattice disorder, which would result in an even amorphous microstructure. ${ }^{12,13}$

In general, as-deposited $\mathrm{Ni}-\mathrm{P}$ alloys with a $\mathrm{P}$ content of 2.2-6.7 wt $\%$ exhibited a poor crystalline structure, whereas a completely amorphous phase of Ni-P alloy was obtained when the P content was higher than $12 \mathrm{wt} \%{ }^{14}$ Therefore, it is conceivable that the asdeposited Ni-P coatings may have a poor crystalline structure. To promote crystallinity and structural change, all the as-deposited samples were annealed at $400{ }^{\circ} \mathrm{C}$, and then the Ni-P alloy coating exhibited a crystalline structure, which was confirmed by the following XRD analysis.

\subsection{Phase transformation analysis}

In this study, after the post-annealing process at $400{ }^{\circ} \mathrm{C}$ the $\mathrm{Ni}-\mathrm{P}$ samples were transformed into a crystalline mixture, as suggested by the black curve at the bottom of Fig. 2(a). Obviously, diffraction lines corresponding to both face-centered cubic (FCC) nickel (labeled as $\mathrm{Ni}(111), \mathrm{Ni}(200)$, and $\mathrm{Ni}(220)$, respectively) and body-centered tetragonal (BCT) $\mathrm{Ni}_{3} \mathrm{P}$ (labeled as $\mathrm{Ni}_{3} \mathrm{P}(112), \mathrm{Ni}_{3} \mathrm{P}(330)$, and $\mathrm{Ni}_{3} \mathrm{P}(141)$, respectively) are observed in the diffractogram, which indicates the equilibrium coexistence of $\mathrm{Ni}$ and $\mathrm{Ni}_{3} \mathrm{P}$ phases in the coatings. It has been confirmed that when the annealing temperature was above $350{ }^{\circ} \mathrm{C}$ precipitation of $\mathrm{Ni}_{3} \mathrm{P}$ occurred from a phosphorus-rich amorphous deposit, which led to lattice disorder in the nickel matrix. ${ }^{15}$ After further quenching, two more $\mathrm{Ni}_{3} \mathrm{P}$ peaks labeled as $\mathrm{Ni}_{3} \mathrm{P}(231)$ and $\mathrm{Ni}_{3} \mathrm{P}(123)$ appeared in the diffraction pattern. The quenching treatment did not affect the peak positions. On the other hand, with an increase in the quenching temperature the intensities of the $\mathrm{Ni}_{3} \mathrm{P}$ peaks increased, which was evidently a result of the complete crystallization of the Ni-P alloys. The hard $\mathrm{Ni}_{3} \mathrm{P}$ precipitates were preferentially located at grain boundaries and triple junctions and acted as an additional barrier to the movement of dislocations..$^{16,17}$

The crystallite sizes of the $\mathrm{Ni}_{3} \mathrm{P}$ and $\mathrm{Ni}$ phases in the quenched Ni-P coatings were calculated by the Debye-Scherrer formula, as shown in Fig. 2(b). Obvious grain refinement of the $\mathrm{Ni}_{3} \mathrm{P}$ phase, as well as the Ni phase, took place at quenching temperatures of $300{ }^{\circ} \mathrm{C}$ and $400{ }^{\circ} \mathrm{C}$. The quenching process played an important role in grain refinement. In this case, the quenching process caused an increase in lattice strain, which greatly reduced the growth rate of crystallites and produced a high density of dislocations around the $\mathrm{Ni}_{3} \mathrm{P}$ precipitates, as well as in the plastic region of the Ni matrix. However, when the quenching temperature was excessively high $\left(>400{ }^{\circ} \mathrm{C}\right)$, a coarsening phenomenon of the $\mathrm{Ni}_{3} \mathrm{P}$ precipitates occurred. An excessively high quenching temperature resulted in the occurrence of diffusion creep and the rapid annihilation of dislocations at grain boundaries, ${ }^{18,19}$ which was accompanied by the 

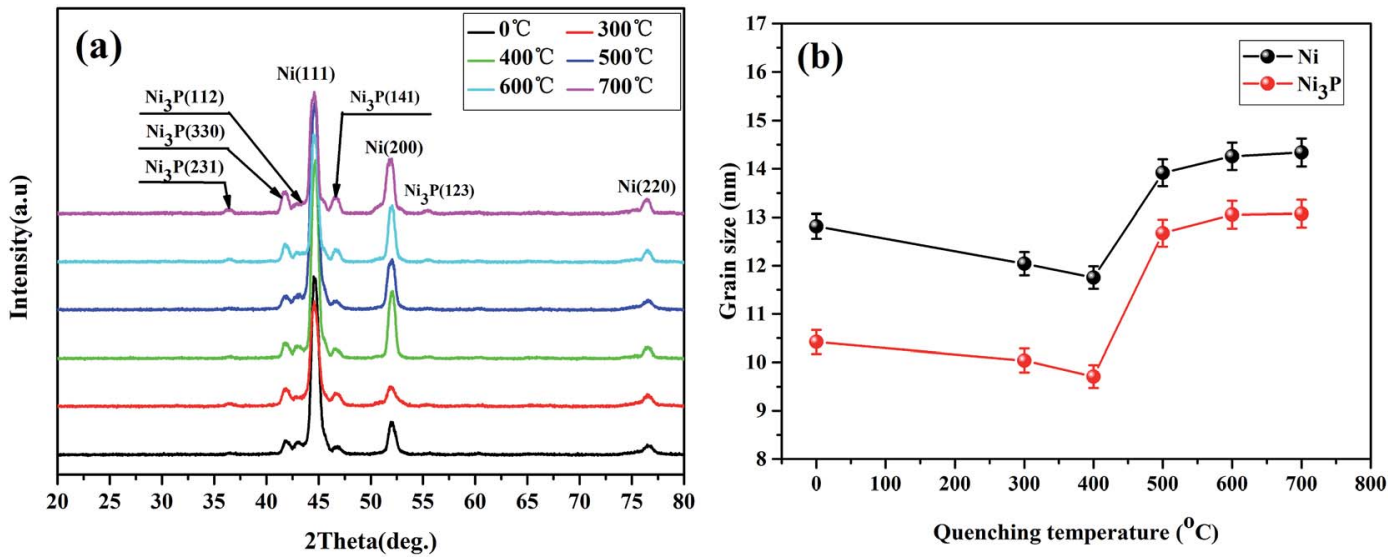

Fig. 2 (a) XRD patterns and (b) variations in grain sizes of $\mathrm{Ni}$ and $\mathrm{Ni}_{3} \mathrm{P}$ of $\mathrm{Ni}-\mathrm{P}$ coatings quenched at different temperatures.

growth of $\mathrm{Ni}_{3} \mathrm{P}$ precipitates. The above analysis shows that an appropriate quenching temperature induced a positive effect on grain refinement of the Ni-P alloy, which would further promote the re-strengthening effect on the hardness and wear resistance of Ni-P coatings.

\subsection{Mechanical properties}

Fig. 3(a) shows the variation in the internal stress of the Ni-P coatings with the quenching temperature. It was found that the as-annealed Ni-P coating displayed a comparatively low internal stress of $106 \pm 5.3 \mathrm{MPa}$, whereas the quenched Ni-P coatings underwent a linear increase in internal stress from 150 to $422 \mathrm{MPa}$ with an increase in the quenching temperature. Furthermore, the adhesive strength of the Ni-P coatings gradually increased from 68 to $75 \mathrm{~N}$ as a result of the increase in the quenching temperature. However, when the quenching temperature was above $600{ }^{\circ} \mathrm{C}$ the adhesive strength sharply declined to $51 \mathrm{~N}$. The above analysis indicates that a great structural change occurred in the Ni-P coatings after the quenching process. An excessively high temperature could contribute to the growth of hard $\mathrm{Ni}_{3} \mathrm{P}$ particles, leading to volume shrinkage and a corresponding increase in internal stress. ${ }^{20} \mathrm{~A}$ higher quenching temperature was beneficial for the achievement of metallurgical adhesion at the interfaces, in particular, for interdiffusion between an $\mathrm{Ni}$ interlayer and Fe-based substrates. The metallurgical intermediate layer competitively reduced the influence of internal stress, and Ni-P coatings could retain higher adhesive strength on steel substrates with a quenching temperature of less than $600{ }^{\circ} \mathrm{C}$, although the internal stress of the coatings increased as the quenching temperature increased. However,

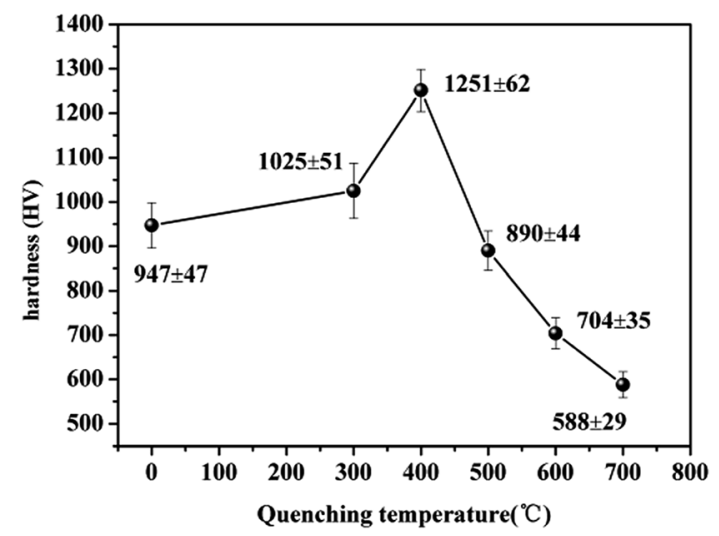

Fig. 4 Variation in hardness of $\mathrm{Ni}-\mathrm{P}$ coatings quenched at different temperatures.
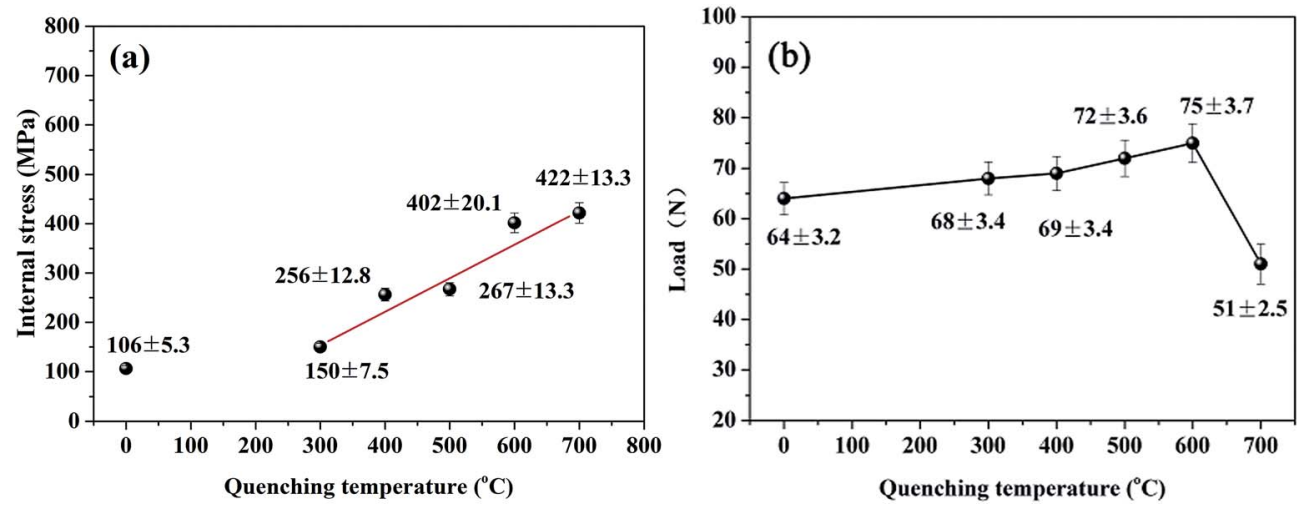

Fig. 3 Variations in (a) internal stress and (b) critical load with quenching temperature for $\mathrm{Ni}-\mathrm{P}$ coatings. 

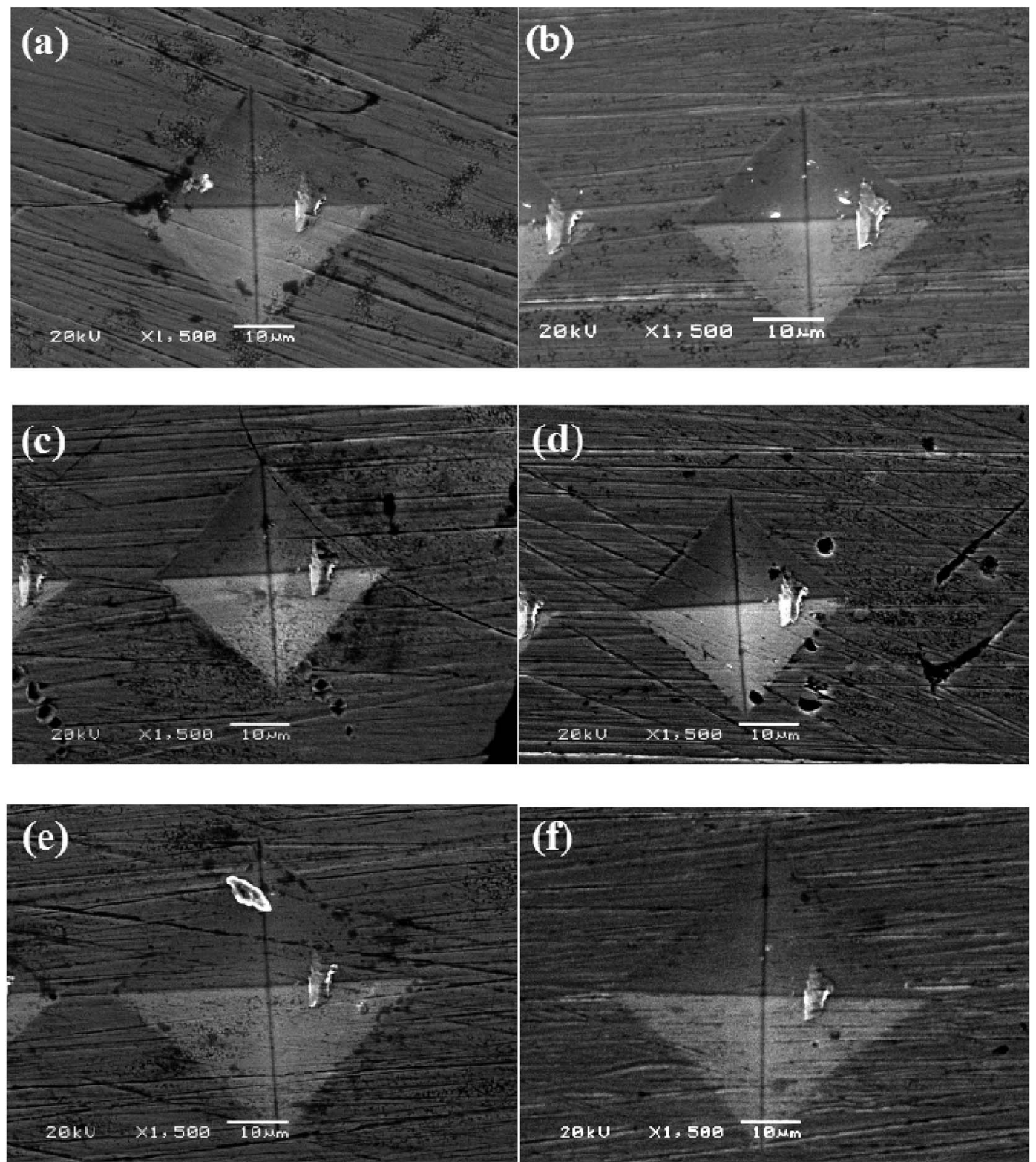

Fig. 5 Imprinted morphologies of Ni-P alloys: (a) as-annealed and quenched at (b) $300{ }^{\circ} \mathrm{C}$, (c) $400{ }^{\circ} \mathrm{C},(\mathrm{d}) 500{ }^{\circ} \mathrm{C}$, (e) $600{ }^{\circ} \mathrm{C}$, and (f) $700{ }^{\circ} \mathrm{C}$.
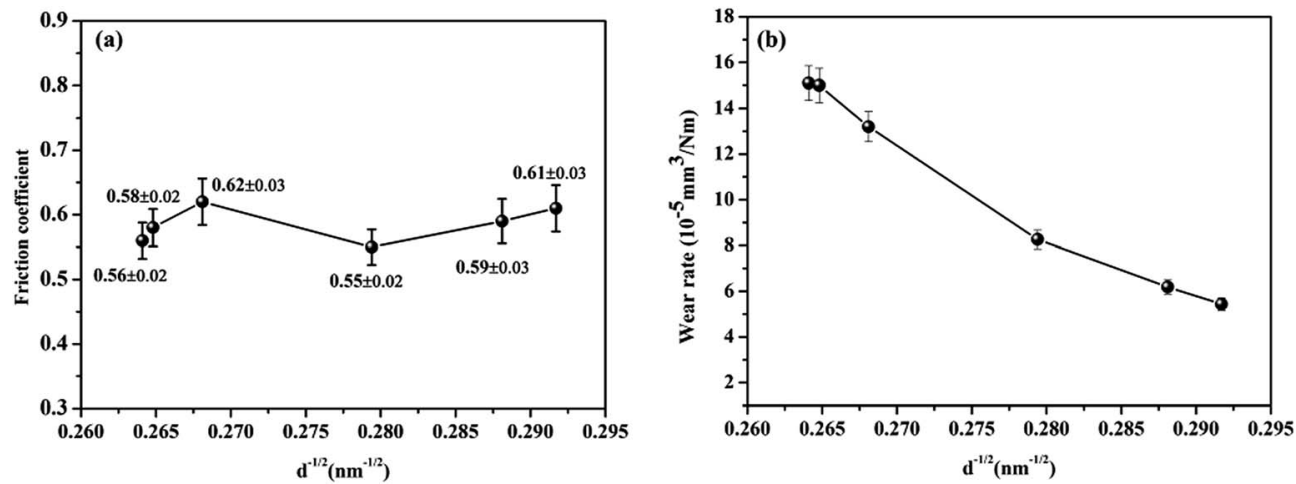

Fig. 6 (a) Average friction coefficients and (b) specific wear rates of $\mathrm{Ni}-\mathrm{P}$ coatings quenched at different temperatures. 
when the quenching temperature rose to $700{ }^{\circ} \mathrm{C}$ the substantial mismatch in thermal expansion coefficients between $\mathrm{Ni}-\mathrm{P}$ coatings and steel substrates would limit the coating-to-substrate adaptive capacity. Thus, the adhesive strength of the coating would be severely impaired by the metallurgical diffusion layer at the interfaces, ${ }^{21}$ as shown in Fig. 3(b).

Fig. 4 shows the hardness of $\mathrm{Ni}-\mathrm{P}$ coatings quenched at different temperatures. In the region of low quenching temperatures $\left(<400{ }^{\circ} \mathrm{C}\right)$, the hardness of the $\mathrm{Ni}-\mathrm{P}$ alloys increased from $947 \mathrm{HV}$ to $1251 \mathrm{HV}$ with an increase in the quenching temperature and then decreased drastically upon a further increase in the quenching temperature above $500{ }^{\circ} \mathrm{C}$. In general, the high hardness of $\mathrm{Ni}-\mathrm{P}$ coatings is mainly contributed by the precipitation hardening of $\mathrm{Ni}_{3} \mathrm{P}$ grains on heat treatment. ${ }^{22,23}$ In this case, the considerable increase in the hardness of the quenched Ni-P alloy was due to the restrengthening effect by the combination of grain refinement and either alloying with $\mathrm{P}$ or the precipitation of $\mathrm{Ni}_{3} \mathrm{P}$, as well as the high dislocation density of the Ni-P alloys. ${ }^{24}$ Thus, when the $\mathrm{Ni}-\mathrm{P}$ coating was quenched at an appropriate temperature $(400$ ${ }^{\circ} \mathrm{C}$ ), the $\mathrm{Ni}_{3} \mathrm{P}$ precipitates acted as barriers to the movement of dislocations, and meanwhile grain refinement occurred, which thereby increased the hardness, as shown in Fig. 4. However, after quenching at excessively high temperatures the hardness of the Ni-P coatings decreased because of coarsening and grain growth of $\mathrm{Ni}_{3} \mathrm{P}$ and the Ni matrix, which would cause volumetric shrinkage within the Ni-P coatings and an increase in the plasticity of the Ni-P alloy.

Fig. 5 shows the imprinted morphologies of Ni-P coatings after microhardness testing at an applied load of $500 \mathrm{~g}$ and a dwell time of $10 \mathrm{~s}$. Obviously, all the coating surfaces exhibited smooth micro-diamond imprinted edges without distinct fracture cracks as the quenching temperature changed from $300{ }^{\circ} \mathrm{C}$ to $700{ }^{\circ} \mathrm{C}$, which implies that the character of the Ni-P samples was highly consistent. Because the hardness decreased as the quenching temperature rose above $500{ }^{\circ} \mathrm{C}$, the indentations became larger, as shown in Fig. 5(e) and (f).

\subsection{Friction and wear properties}

Fig. 6(a) shows the relationship between the average friction coefficient and the reciprocal square-root grain size $\left(d^{-1 / 2}\right)$. The friction coefficient of the samples underwent a small fluctuation between 0.55 and 0.65 as $d^{-1 / 2}$ increased (i.e., the grain size decreased), which was attributed to inhomogeneous precipitates of phosphides and intermetallic phases. The results for the wear rates of the Ni-P coatings are presented in Fig. 6(b). The overall wear trend shows that the wear rate decreased as $d^{-1 / 2}$ increased. This result is known as the inverse Hall-Petch relationship. However, our results showed that the grain size decreased until the quenching temperature was $400{ }^{\circ} \mathrm{C}$. Theoretically, there should be a decline in the wear rate with an increase in $d^{-1 / 2}$. This inverse Hall-Petch effect could be ascribed to the absence of the accumulation of dislocations, the occurrence of diffusion creep, the rapid annihilation of dislocations at grain boundaries and softening caused by the presence of a significant number of grain triple junctions. ${ }^{20}$
However, a complete explanation was not fully deduced from our experimental results. There was a consensus that the quenching process at an appropriate temperature had a re-
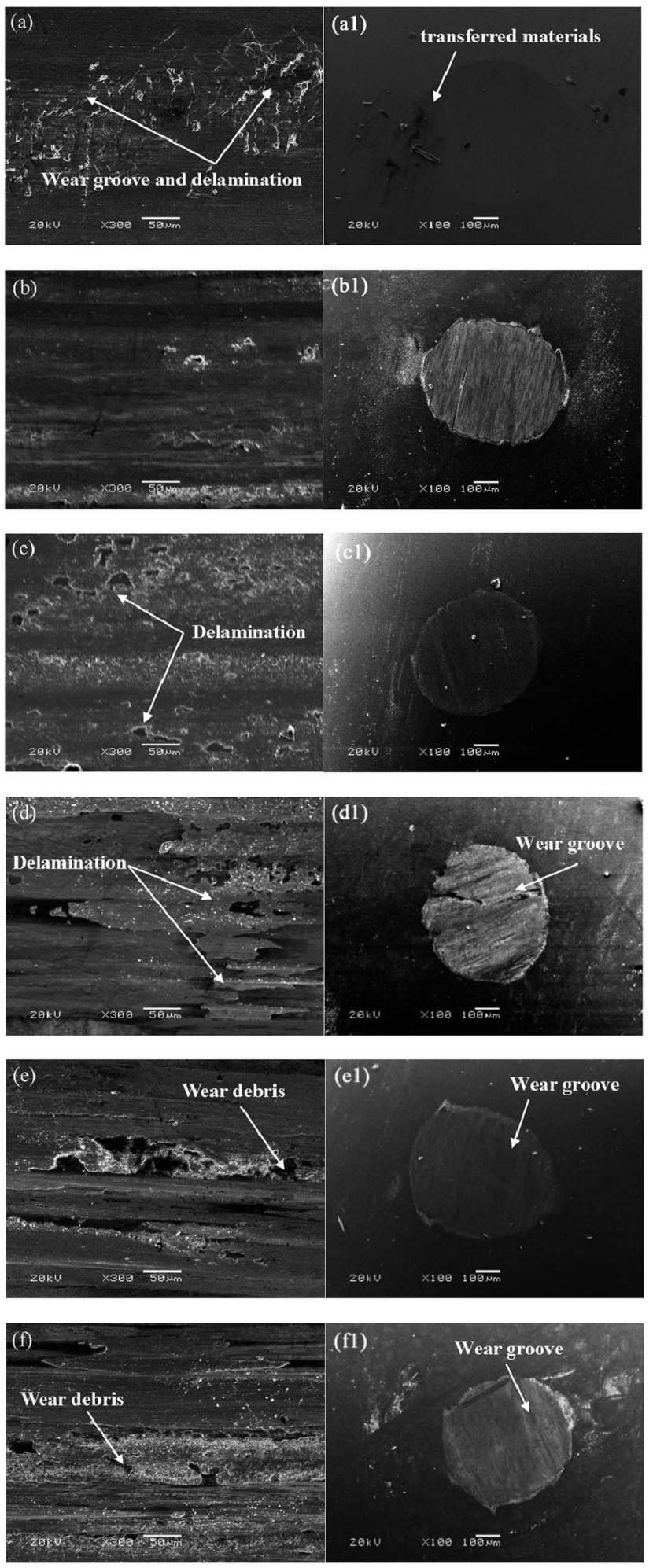

Fig. 7 SEM observations showing the features of wear tracks and wear scars on pair surfaces for $\mathrm{Ni}-\mathrm{P}$ deposits as-annealed (a and a1) and quenched at $300{ }^{\circ} \mathrm{C}\left(\mathrm{b}\right.$ and b1), $400{ }^{\circ} \mathrm{C}$ ( $\mathrm{c}$ and $\left.\mathrm{c} 1\right), 500{ }^{\circ} \mathrm{C}$ ( $\mathrm{d}$ and $\mathrm{d} 1$ ), $600^{\circ} \mathrm{C}$ (e and e1), and $700{ }^{\circ} \mathrm{C}$ ( $f$ and f1), respectively. 
strengthening effect on the hardness and wear resistance of the $\mathrm{Ni}-\mathrm{P}$ coatings.

The wear track of the as-annealed Ni-P sample displays obvious wear grooves and delamination of the coating to a large extent, which implies abrasive wear and severe plastic deformation, as shown in Fig. 7(a). However, a smooth wear scar could be observed, with some transferred materials scattered around the wear scar of the counter ball (Fig. 7(a1)). As shown in Fig. $7(\mathrm{c}, \mathrm{d})$ and $(\mathrm{c} 1, \mathrm{~d} 1)$, the Ni-P coatings quenched at $300{ }^{\circ} \mathrm{C}$ and $400{ }^{\circ} \mathrm{C}$ show that the extent of plastic deformation decreased, and the features of delamination were replaced by numerous discontinuous oxygen-containing debris layers, which resulted in a decrease in the wear rate, as was the case for the counterparts. The reduction in plastic deformation was ascribed to the increase in hardness and reduction in grain size, as shown in Fig. 6. With a further increase in the quenching temperature the wear debris became continuous. The wear mechanism of the Ni-P coatings was mainly dominated by adhesive wear accompanied by a combination of abrasion and oxidation wear, as shown in Fig. 7(d-f). The counterparts, which display irregular grooving and a fraction of abraded debris along the sides surrounding the wear track, are shown in Fig. 7(d1-f1) and indicate that a large extent of abrasion wear was the dominant wear mechanism. Owing to the increase in grain size, the coatings displayed an increase in internal stress and a decrease in hardness, which increased the risk of adhesive wear of the Ni-P coatings and abrasive wear of the corresponding counterparts. In summary, the grain size effect of the Ni-P coatings had an inherent effect on the evolution of the wear track, as shown in Fig. 6(b).

\section{Conclusions}

Electrodeposited Ni-P coatings with phosphorus contents of $4.44 \mathrm{wt} \%$ were fabricated using a direct electrodeposition technique. After being annealed at $400{ }^{\circ} \mathrm{C}$, the $\mathrm{Ni}-\mathrm{P}$ coatings were further subjected to quenching treatment. After investigations of the structures and mechanical properties, as well as the wear behavior, of $\mathrm{Ni}-\mathrm{P}$ coatings quenched at various temperatures, our conclusions can be summarized as follows:

(1) The quenching process induced a microstructural evolution of the Ni-P coatings. The appropriate quenching temperature had a positive effect on grain refinement of the annealed Ni-P coatings. Obvious grain refinement of the $\mathrm{Ni}_{3} \mathrm{P}$ phase, as well as the $\mathrm{Ni}$ phase, took place at quenching temperatures of $300{ }^{\circ} \mathrm{C}$ and $400{ }^{\circ} \mathrm{C}$.

(2) The employment of the quenching process on the annealed $\mathrm{Ni}-\mathrm{P}$ coatings resulted in great improvements in hardness and wear resistance, which greatly contributed to the re-strengthening effect of the combination of the grain size effect and dispersion of $\mathrm{Ni}_{3} \mathrm{P}$.

(3) The wear rate of the heat-treated coatings decreased as $d^{-1 / 2}$ increased, which indicates that the relationship between the strength and grain size for the re-strengthening $\mathrm{Ni}-\mathrm{P}$ coatings followed the inverse Hall-Petch relationship.

\section{Acknowledgements}

The authors are grateful to the National Natural Science Foundation of China (Grant No. 21373249 and 51322508) for financial support.

\section{References}

1 K. H. Hou, H. T. Wang and H. H. Sheu, Appl. Surf. Sci., 2014, 308, 372.

2 L. Elias and A. C. Hegde, Surf. Coat. Technol., 2015, 283, 61.

3 H. Yang, Y. Gao and W. Qin, Surf. Coat. Technol., 2015, 281, 176.

4 J. W. Qiao, Z. Wang and L. W. Ren, J. Mater. Sci. Eng. A, 2016, 657, 353.

5 M. C. Chou, H. Yang and S. H. Yeh, Microsyst. Technol., 2001, 7, 36.

6 A. Ahmad, K. M. Ghauri and L. Ali, Pakistan Journal of Engineering and Applied Sciences, 2013, 12, 20.

7 S. C. Mehta, D. A. Smith and U. Erb, J. Mater. Sci. Eng. A, 1995, 204, 227.

8 H. Tanabe, K. Ogawa and Y. Izumi, Adv. Mater. Res., 2012, 566, 427.

9 R. S. Razavi, M. Salehi and M. Monirvaghefi, ISIJ Int., 2007, 47, 709.

10 Z. G. Qiu, H. Y. Yu and L. Z. Zhao, Thin Solid Films, 2016, 604, 12.

11 M. Caul and V. Randle, Mater. Charact., 1997, 38, 155.

12 A. M. Pillai, A. Rajendra and A. K. Sharma, J. Coat. Technol. Res., 2012, 9, 785.

13 G. McMahon and U. Erb, J. Mater. Sci. Lett., 1989, 8, 865.

14 Y. F. Shen, W. N. Liu and X. Sun, Metall. Mater. Trans. A, 2012, 43, 1610.

15 I. Apachitei, F. D. Tichelaar and J. Duszczyk, Surf. Coat. Technol., 2002, 149, 263.

16 K. G. Keong, W. Sha and S. Malinov, J. Alloys Compd., 2001, 334, 192.

17 T. hentschel, D. Isheim and R. kirchheim, Acta Mater., 2000, 48, 933.

18 I. Apachitei and J. Duszczyk, Surf. Coat. Technol., 2000, 132, 89.

19 T. G. Nieh and J. G. Wang, Intermetallics, 2005, 13, 377.

20 L. P. Wang, Y. Gao and T. Xu, Appl. Surf. Sci., 2006, 252, 7361.

21 S. B. Hu, J. P. Tu and Z. Mei, Surf. Coat. Technol., 2001, 141, 174.

22 Y. F. Shen, W. Y. Xue and Z. Y. Liu, Surf. Coat. Technol., 2010, 205, 632.

23 D. H. Jeong, U. Erb and K. T. Aust, Scr. Mater., 2003, 48, 1067.

24 E. Pellicer, A. Varea and K. M. Sivaraman, ACS Appl. Mater. Interfaces, 2011, 3, 2265. 